\title{
Genome-wide gene expression profiling suggests distinct radiation susceptibilities in sporadic and post-Chernobyl papillary thyroid
}

\section{cancers}

\author{
V Detours*, I,5, L Delys',5, F Libert', D Weiss Solís', T Bogdanova², JE Dumont', B Franc ${ }^{3}$, G Thomas $^{4}$, \\ C Maenhaut'
}

'Institute of Interdisciplinary Research, School of Medicine, Univertisté Libre de Bruxelles (ULB), Campus Erasme, CP602, route de Lennik 808, Brussels B-1070, Belgium; ' Institute of Endocrinology and Metabolism, Kiev 04I I4, Ukraine; ${ }^{3}$ Service d'Anatomie et de Cytologie Pathologiques, APHP (Hôpital Ambroise Paré), Faculté de Médecine Paris lle de France Ouest, Université Versailles Saint-Quentin en Yvelines, 9 Avenue Charles de Gaulle, Boulogne 92100, France; ${ }^{4}$ South West Wales Cancer Institute/Swansea Clinical School, Singleton Hospital, Sketty Lane, Swansea SA2 8QA, UK

Papillary thyroid cancers (PTCs) incidence dramatically increased in the vicinity of Chernobyl. The cancer-initiating role of radiation elsewhere is debated. Therefore, we searched for a signature distinguishing radio-induced from sporadic cancers. Using microarrays, we compared the expression profiles of PTCs from the Chernobyl Tissue Bank (CTB, $n=12$ ) and from French patients with no history of exposure to ionising radiations $(n=14)$. We also compared the transcriptional responses of human lymphocytes to the presumed aetiological agents initiating these tumours, $\gamma$-radiation and $\mathrm{H}_{2} \mathrm{O}_{2}$. On a global scale, the transcriptomes of CTB and French tumours are indistinguishable, and the transcriptional responses to $\gamma$-radiation and $\mathrm{H}_{2} \mathrm{O}_{2}$ are similar. On a finer scale, a II 8 genes signature discriminated the $\gamma$-radiation and $\mathrm{H}_{2} \mathrm{O}_{2}$ responses. This signature could be used to classify the tumours as $\mathrm{CTB}$ or French with an error of 15-27\%. Similar results were obtained with an independent signature of 13 genes involved in homologous recombination. Although sporadic and radio-induced PTCs represent the same disease, they are distinguishable with molecular signatures reflecting specific responses to $\gamma$-radiation and $\mathrm{H}_{2} \mathrm{O}_{2}$. These signatures in PTCs could reflect the susceptibility profiles of the patients, suggesting the feasibility of a radiation susceptibility test.

British Journal of Cancer (2007) 97, 818-825. doi: I0.1038/sj.bjc.6603938 www.bjcancer.com

Published online 21 August 2007

(c) 2007 Cancer Research UK

Keywords: thyroid cancers; Chernobyl; radiation susceptibility; microarray

An increased incidence of thyroid carcinomas in children was first noticed in Belarus and Ukraine 4 years after the 1986 Chernobyl accident (Baverstock et al, 1992; Kazakov et al, 1992). Increased incidence has been observed since then in people exposed to fallout during childhood in these regions (United Nations Scientific Committee of the Effect of Atomic Radiation, 2000; Mahoney et al, 2004). The aggressiveness and morphology of these tumours (over $95 \%$ classified on the basis of their pathology as papillary thyroid carcinomas (PTCs)) appear to be related to the age of the patients at the time of the accident and to the lag between the accident and diagnosis, that is, the latency of the cancers (Williams et al, 2004).

Radiation is the only proven cause of PTC so far. Although the cause of PTC in patients not exposed to radiation remains uncertain, a growing body of evidence suggests that $\mathrm{H}_{2} \mathrm{O}_{2}$ could play a role in the absence of radiation. Indeed, it is a potent DNAdamaging agent produced in large amounts during thyroid hormone synthesis (Corvilain et al, 2000). It causes DNA damage (guanine oxidation, single- and double-strand breaks) in human

*Correspondence: Dr V Detours; E-mail: vdetours@ulb.ac.be

${ }^{5}$ These authors contributed equally to this work.

Received 8 May 2007; revised 24 July 2007; accepted 24 July 2007; published online 21 August 2007 lymphocytes (Turner et al, 2003), hamster ovarian cells (DahmDaphi et al, 2000; Mondello et al, 2002), and in human, dog and sheep thyroid cells in primary culture (Chico Galdo et al, 2006). Hydrogen peroxide is believed to destroy follicular thyroid cells in myxoedematous endemic cretinism (Kohrle et al, 2005) and to cause cancers in the thyroid of $\mathrm{Tg}-\alpha_{1 \mathrm{~B}} \mathrm{AR}$ mice (Ledent et al, 1997). Lack of protective systems, peroxiredoxin or glutathione peroxidases, in knockout mice lead to cancer (Neumann et al, 2003; Lee et al, 2006). Transfection of an $\mathrm{H}_{2} \mathrm{O}_{2}$-generating system transform epithelial cells (Chu et al, 1996). The spontaneous somatic mutation rate in normal mice and rat thyroid cells is substantially higher than in liver and lung cells (Corvilain et al, 1994). With a turnover of 8.5 years in adults (Coclet et al, 1989), thyrocytes have time to accumulate $\mathrm{H}_{2} \mathrm{O}_{2}$-induced DNA damages. Hydrogen peroxide has been found to play a role in several human cancers (Quinn et al, 2006). Thus, a number of arguments support a role of $\mathrm{H}_{2} \mathrm{O}_{2}$ in the initiation of PTC, and in particular in patients not exposed to radiation.

The vast majority of PTCs harbour either a BRAF mutation (45\%; Xing, 2005) or a RET/PTC rearrangement (35\% in adults; Nikiforov, 2002), which are generally mutually exclusive (Soares et al, 2003). Both gene alterations result in the constitutive activation of the RAS-RAF-MAPK signalling pathway (Kimura et al, 2003; Soares et al, 2003). Gene-expression signatures separating BRAF from RET/PTC tumours have been reported, 
but the number of genes involved varies from a few dozens (Frattini et al, 2004) to several thousands (Giordano et al, 2005). Although early reports pointed at a lower BRAF mutation frequency in Chernobyl patients, recent evidence suggests that the BRAF mutation is associated with age and is more prevalent among older Chernobyl patients and/or among patients with longer latency tumours (Kumagai et al, 2004; Lima et al, 2004; Powell et al, 2005; Rosenbaum et al, 2005). Several research teams have reported higher frequencies of RET/PTC rearrangements in post-Chernobyl patients (Nikiforov et al, 1997). These higher frequencies could result from the fact that radiation induces double-strand breaks, and thus rearrangements rather than point mutations (Dahm-Daphi et al, 2000), or possibly to a differing molecular profile in childhood $v s$ adult papillary carcinomas (Powell et al, 2005). The induction of RET/PTC rearrangements after in vitro irradiation of immortalised thyroid cells (Caudill et al, 2005) supports the former explanation. Whether the two best-characterised genetic alterations found in PTC are involved in a radiation signature remains an open question. In addition, radiation induces other unknown alterations.

In this paper, we have compared the gene-expression profiles of PTCs from adult French patients with no history of exposure to radiation and from adult Ukrainian patients exposed to Chernobyl fallout during childhood, and asked whether there is a geneexpression signature distinguishing radiation-induced from sporadic cancers. Our preliminary investigation suggested the absence of a large-scale radiation signature (Detours et al, 2005). We extend it here by using a more recent microarray technology, by covering more genes, by studying more patients and by establishing results with a wider range of statistical methods. We confirm that French and Chernobyl Tissue Bank (CTB) tumours have the same overall expression profiles and have indistinguishable BRAF and RET/PTC frequencies.

We also compared the transcriptional responses of human cells to the two most likely aetiological agents of CTB and French tumours; $\gamma$-radiation and $\mathrm{H}_{2} \mathrm{O}_{2}$. The similarity of $\mathrm{CTB}$ and French tumours is mirrored by the similarity of the transcriptional responses to $\gamma$-radiation and $\mathrm{H}_{2} \mathrm{O}_{2}$. However, subtle expression differences are exploitable to accurately classify these tumours according to their origin. Part of these expression differences includes genes involved in the differential response to $\mathrm{H}_{2} \mathrm{O}_{2}$ and radiation, and genes involved in homologous recombination which suggests that different-and detectable-susceptibility profiles lead to sporadic and radiation-induced PTC.

\section{MATERIALS AND METHODS}

\section{Transcriptional and genetic data}

Paired samples of tumoral and adjacent non-tumoral thyroid tissues were obtained from the CTB (www.chernobyltissuebank.com) and from patients undergoing surgery for thyroid disease at the Ambroise Pare Hospital (Boulogne, France). French tissues were immediately frozen in liquid nitrogen and stored at $-80^{\circ} \mathrm{C}$ until use. Diagnoses were made by the Department of Pathology at the Ambroise Pare Hospital or by the International Pathology Panel of the CTB. The protocol received approval from the Ethics Committees of the institutions. The detail of BRAF-RET/PTC status determination, RNA processing and microarray data preprocessing is available in Supplementary information file S3. Microarray data are available from the Gene Expression Omnibus (www.ncbi.nlm.nih.gov/geo), accession number GSE3950.

\section{Comparison of microarray platforms}

Jarzab et al (2005) data were downloaded from www.genomika.pl/ thyroidcancer/PTCCancerRes.html. We used the original MAS 5.0 normalised expression levels, took the $\log _{2}$ of expression ratios and averaged over patients. The probes of the two platforms could be matched on the basis of their Entrez IDs for 4203 genes.

\section{Unsupervised classification}

Hierarchical clustering was computed with the $\mathrm{R}$ language function hclust with Ward linkage. Multidimensional scaling was computed with the $\mathrm{R}$ function isoMDS. Both methods were fed Pearson correlation distances as input.

\section{Supervised classification}

Support vector machine classification was run with linear kernel and cost $=1$ using the rfe 0.2 and e1071 1.5.9 packages for R. The generalised partial least-square (GPLS) implementation from package gpls 1.1.0 (Ding and Gentleman, 2004) for R was run with default parameters. Prediction analysis of microarray (Tibshirani et al, 2002) was run with threshold values in $\{1.0$, $1.1,1.2, \ldots, 3.0\}$ using pamr 1.25 for $\mathrm{R}$. The random forest classification used default parameters from $\mathrm{R}$ package randomForest 4.5.12 (Zhang et al, 2003). Generalised partial least-square and random forest (RF) were combined with an external genes selection procedure focusing on the $n$ genes with the highest absolute $t$-statistics, with $n$ in $\left\{1,2^{1}, 2^{2}, \ldots, 2^{13}\right\}$. We adopted the inner/outer cross-validation scheme described in details in Ruschhaupt et al (2004) and implemented in the package MCRestimate 1.3.0 to prevent parameter and gene selection biases (Ambroise and McLachlan, 2002). Note that a simpler split-sample validation, in which samples are not recycled as in the current cross-validation protocol, would be suboptimal here because of the limited availability of CTB samples (Simon et al, 2003). A 13-fold cross-validation protocol with each round including parameter and gene selection, and classification was run. At each one of the 13 rounds, the best parameters (including signature size) were estimated by running a nested (inner) 12-fold cross-validation for each combination of parameters. Table 2 presents averages over 10 repetitions of the entire inner/outer cross-validation, each based on a different random 13-fold partitions of the data. The random error was computed by averaging the error of five runs of the complete classification procedure on data with CTB and French labels randomly assigned to samples. The same protocol was used for the classification on the basis of the 118 genes $\gamma$-radiation $v s$ $\mathrm{H}_{2} \mathrm{O}_{2}$ signature, except that the number of genes, $n$, was chosen in $\{1,5,10, \ldots, 118\}$ and that the tested prediction analysis of microarray (PAM) thresholds were in $\{0.1,0.2, \ldots, 3.0\}$. Classifications on the basis of DNA repair signatures were run without gene selection, and therefore without inner crossvalidation. The PAM threshold was set to 0.5. All $P$-values were derived by running 1000 times the complete cross-validation with CTB and French labels assigned randomly to samples and counting how many runs produced classification error below the error obtained on the actual data.

\section{Derivation of the $\gamma$-radiation $v s \mathrm{H}_{2} \mathrm{O}_{2}$ signature}

We downloaded the Supplementary data set S2 of Amundson et al (2005) from the Oncogene web site (www.nature.com/onc/ index.html). Genes with expression values differing by 1.5 -fold between the $2.5 \mathrm{~Gy} \gamma$-radiation- and $\mathrm{H}_{2} \mathrm{O}_{2}(200 \mu \mathrm{M})$-treated TK6 cells were selected. To remove immune system-related genes, we downloaded the gcrma-processed version of the GNF human gene atlas (Su et al, 2004; symatlas.gnf.org), which contains expression profiles of normal tissues in most organs. We performed an unpaired two class Significance Analysis of Microarrays (SAM; Tusher et al, 2001) with class no. 1 including immune systemrelated tissues and white blood cells and class no. 2 including all other tissues. We selected the $20 \%$ top-ranking genes, which were 
all significant at $q<0.05$, and removed them from the $\gamma$-radiation and $\mathrm{H}_{2} \mathrm{O}_{2}$ signature.

\section{RESULTS}

Expression profiles and gene alteration status of PTCs from France and from the Chernobyl Tissue Bank

Expression profiles were determined for the tumours of 14 patients from France with no documented history of exposure to radiation, and 12 tumours from the Chernobyl Tissue Bank (see online Materials and Methods). CTB tumours are papillary cancers collected in young people who were exposed to the Chernobyl accident ((Thomas et al, 2000), see patient information, Table 1). There are 9 tumours of classical subtype, 4 of follicular subtype and 1 of trabecular subtype among the 14 French PTC samples. There are 8 classical, 3 follicular and 1 solid subtypes among the 12 CTB PTC samples. Three French and four CTB mRNA samples (PTC6, PTC7, PTC11 and S405, S420, S422, S423) were reused from our earlier study (Detours et al, 2005).

The mRNA expression profiles of all tumours were determined with 12000 EST (8000 genes) cDNA microarrays using patientmatched nontumoural adjacent tissues as controls. To assess the quality of the data, we compared our expression ratios averaged over samples with those of Jarzab et al (2005), who used the Affymetrix ${ }^{\mathrm{R}}$ platform. Pearson's correlation measured on the $\sim 4000$ genes available and expressed in both platforms was 0.72 (Figure 1).

Tumours were screened for the presence of a RET/PTC rearrangement and for BRAF V600E mutation (Table 1). A RET/ PTC rearrangement was found in $42 \%(5 / 12)$ of the CTB tumours and in $21 \%(3 / 14)$ of the French tumours. The difference between the two groups is not significant according to Fisher's exact test. The BRAF mutation is found in comparable proportions in French $(36 \%, 5 / 14)$ and CTB tumours $(41 \%, 5 / 12)$. None of these alterations was detected in $30 \%(8 / 26)$ of the tumours.

Table I Patient information and gene alterations

\begin{tabular}{lcccccc}
\hline $\begin{array}{l}\text { Sample } \\
\text { ID }\end{array}$ & Origin & Sex & $\begin{array}{c}\text { Age in } \\
\mathbf{1 9 8 6}\end{array}$ & $\begin{array}{c}\text { Age at } \\
\text { operation }\end{array}$ & BRAF & $\begin{array}{c}\text { RET/ } \\
\text { PTC }\end{array}$ \\
\hline PTC11 & FR & F & 22 & 37 & - & - \\
PTC14 & FR & M & 17 & 32 & - & - \\
PTC18 & FR & F & NA & 59 & + & - \\
PTC19 & FR & M & 54 & 68 & - & + \\
PTC20 & FR & F & 54 & 68 & + & - \\
PTC21 & FR & F & 39 & 54 & - & + \\
PTC22 & FR & F & 44 & 60 & - & - \\
PTC23 & FR & M & 17 & 33 & - & - \\
PTC25 & FR & F & 49 & 60 & - & - \\
PTC26 & FR & F & 36 & 47 & + & - \\
PTC6 & FR & M & 24 & 37 & - & - \\
PTC7 & FR & F & 13 & 29 & + & - \\
PTC8 & FR & M & 22 & 36 & - & + \\
PTC9 & FR & F & 24 & 38 & + & - \\
S404 & CTB & F & 1 & 16 & - & - \\
S405 & CTB & F & 1 & 16 & - & + \\
S409 & CTB & F & 11 & 28 & + & - \\
S4I4 & CTB & F & 16 & 33 & - & + \\
S415 & CTB & M & 12 & 28 & + & - \\
S418 & CTB & M & 10 & 27 & + & - \\
S420 & CTB & F & 12 & 28 & - & - \\
S422 & CTB & M & 15 & 31 & + & - \\
S423 & CTB & F & 5 & 22 & + & - \\
S425 & CTB & M & 3 & 19 & - & + \\
V519 & CTB & F & 2 & 18 & - & + \\
V608 & CTB & F & 15 & 32 & - & + \\
\hline F & & & & + \\
\hline
\end{tabular}

$\mathrm{F}=$ female; $F R=$ France; $\quad C T B=$ Chernobyl Tissue Bank; $M=$ male; $N A=$ not available; PTC $=$ papillary thyroid cancer.
Chernobyl Tissue Bank and French PTCs have similar overall expression profiles

We first searched for global expression differences between CTB and French PTCs, that is, extensive differences detectable when all the genes present on our arrays are considered. Hierarchical

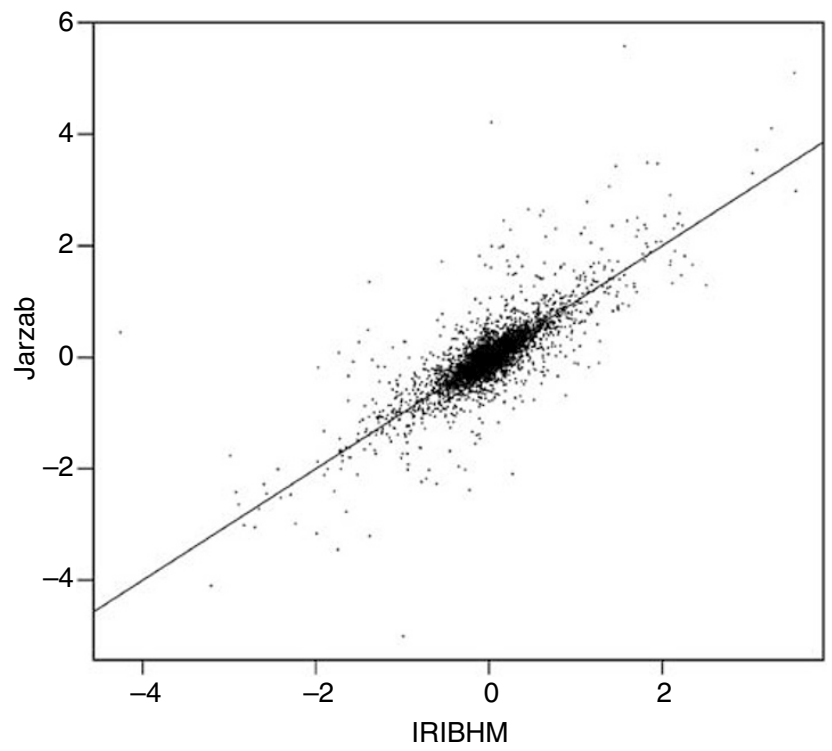

Figure I IRIBHM vs Jarzab et al. (2005) microarray data. Pearson correlation between patient-averaged $\log _{2}$ tumour/normal ratios of the two studies is 0.72 .
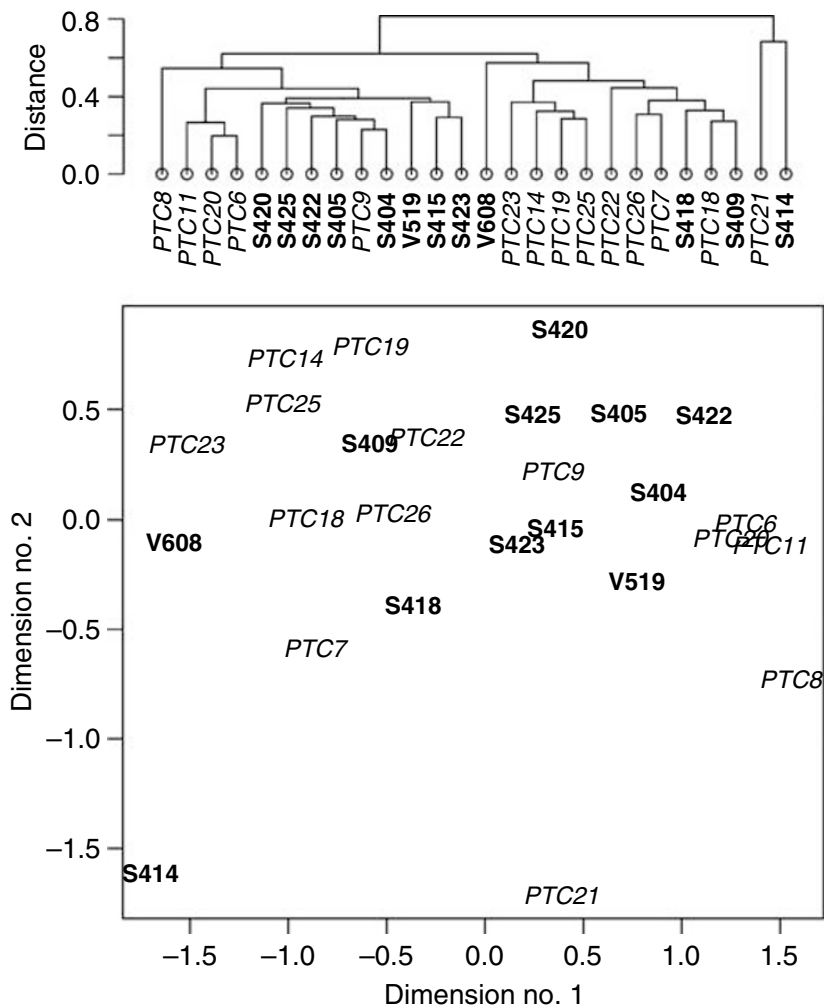

Figure 2 Global expression profiles. Top panel: hierarchical clustering on the basis of all genes. Bottom panel: multidimensional scaling on the basis of all genes. Distances in the two dimensions space were on average distorted by $11 \%$ compared to the actual 8000 dimensions gene space distances Chernobyl Tissue Bank tumours are in bold font, French tumours in italics. 
clustering based on all genes did not reveal a clear separation between these two classes of PTCs (Figure 2, upper panel).

Multidimensional scaling collapses the high-dimensional genes space into two dimensions while preserving the distance relationships between all pairs of samples (Figure 2, lower panel). Figure 2 confirms that French and CTB tumours have similar expression profiles when compared on a global scale although CTB tumours form a more compact group.

\section{Four supervised classification algorithms find multigenes signatures separating CTB from French PTCs}

The absence of separation between CTB and French PTCs on the basis of all genes or at the level of individual genes, does not exclude that these tumours are distinguishable on the basis of a subset of genes. We investigated this possibility with a supervised classification approach (details in Materials and Methods). To strengthen the reliability of our conclusions, all the results were reproduced with four linear classification procedures: linear kernel support vector machines (LKSVM), GPLS, PAMs and RF. Each one included or was combined with a gene selection procedure, that is, a procedure to uncover multigenes signatures including as few genes as possible. All four approaches were tested using a rigorous inner/outer cross-validation procedure (Materials and Methods). It guaranteed that classification testing was performed on independent samples not used for classifier training. The cross-validation results are presented in Table $2 \mathrm{~A}$.

The best performer was GPLS. It misclassified $17 \%$ of CTB tumours as French PTC, 7\% of French PTCs as CTB, resulting in an overall error rate of $12 \%$. Running the same classification on data in which the 'CTB' and 'French' labels were randomly assigned to the 26 tumour samples led to high error rates of $45 \%(n=5$, s.d. $=12 \%$, see Materials and Methods), as expected for random classification of slightly unbalanced classes (12 CTB and 14 French samples). Thus, the low error rates were unlikely to result from artefacts, including data overfitting. Figure 3 shows the 256 most classifying genes found by GPLS/t-statistics trained on all 26 samples (corresponding genes listed in Supplementary Table S1). The optimal signature size varied among the different crossvalidation runs from one gene to several thousands of genes, with a median of 256 genes. Such limited stability is widespread,

Table 2 Error rates for supervised classification

\begin{tabular}{|c|c|c|c|c|}
\hline & French error & CTB error & Global error & \\
\hline \multicolumn{5}{|c|}{ (a) Classification based on all genes } \\
\hline GPLS & 17 & 7 & 12 & \\
\hline PAM & 25 & 29 & 27 & \\
\hline RF & 33 & 14 & 23 & \\
\hline LKSVM & 25 & 7 & 15 & \\
\hline \multicolumn{5}{|c|}{ (b) Classification based on $\mathrm{H}_{2} \mathrm{O}_{2}$ vs $\gamma$-radiation signature } \\
\hline GPLS & 8 & 21 & 15 & \\
\hline PAM & 25 & 29 & 27 & \\
\hline RF & 42 & 7 & 23 & \\
\hline \multirow[t]{2}{*}{ LKSVM } & 25 & 7 & 15 & \\
\hline & French error & CTB error & Global error & $\boldsymbol{P}$ \\
\hline \multicolumn{5}{|c|}{ (c) Classification based on homologous radiation signature } \\
\hline GPLS & 17 & 21 & 19 & 0.0038 \\
\hline PAM & 25 & 21 & 23 & $<0.001$ \\
\hline $\mathrm{RF}$ & 42 & 21 & 31 & 0.063 \\
\hline LKSVM & 8 & 21 & 15 & 0.0038 \\
\hline
\end{tabular}

$\mathrm{CTB}=$ Chernobyl $\quad$ Tissue $\quad$ Bank; $\quad$ GPLS = generalised partial least-square; LKSVM=linear kernel support vector machines; PAM=prediction analysis of microarray; $\mathrm{RF}=$ random forest. Classification and validation procedures are described in Materials and Methods. including in large studies (Ein-Dor et al, 2005; Michiels et al, 2005). The three other classification procedures, LKSVM/RFE, RF/ $t$-test and PAM produced a global error of 15,23 and $27 \%$, respectively. Thus, undirected selections of classifying genes lead to separation CTB and French tumours.

Note that if the classification results were confined to a subtype, the accuracy would not be as low as $15 \%$, it would be greater than $35 \%$ - the classical subtype is the largest, representing $65 \%$ of our tumours.

\section{Hydrogen peroxide and $\gamma$-radiation elicit similar transcriptional responses in lymphocytes}

Because hydrogen peroxide, $\mathrm{H}_{2} \mathrm{O}_{2}$, is produced at high levels during thyroid hormone synthesis (Corvilain et al, 2000) and is a well-known DNA-damaging agent, we investigated the possibility that in the absence of an obvious external risk factor, for example radiation, French cancers must have occurred as a result of $\mathrm{H}_{2} \mathrm{O}_{2}$ exposure.

Amundson et al (2005) measured with microarrays the transcriptional responses of a B-lymphocyte cell line, TK6, to 13 stress agents. These included 10 DNA-damaging agents: $\mathrm{H}_{2} \mathrm{O}_{2}$, radiation (neutron and $\gamma$-rays at 2.5 and $8 \mathrm{~Gy}$ ), adriamycin, arsenite, campothecin, $\mathrm{CdCl}_{2}$, cisplatin, methyl methanesulphonate and UVB $(280-320 \mathrm{~nm})$. We downloaded the expression data published with the paper and produced the hierarchical clustering shown in Figure 4 (see online Materials and Methods). The responses to $200 \mu \mathrm{M} \mathrm{H} \mathrm{H}_{2} \mathrm{O}_{2}$ and to $2.5 \mathrm{~Gy} \gamma$-radiation clustered together, that is, among 12 stress agents, including 10 DNAdamaging agents, $\gamma$-radiation at $2.5 \mathrm{~Gy}$ elicited the transcriptional response that was the closest to that of $\mathrm{H}_{2} \mathrm{O}_{2}$. We concluded that these similar transcriptional responses reflect similar damages in the cells.
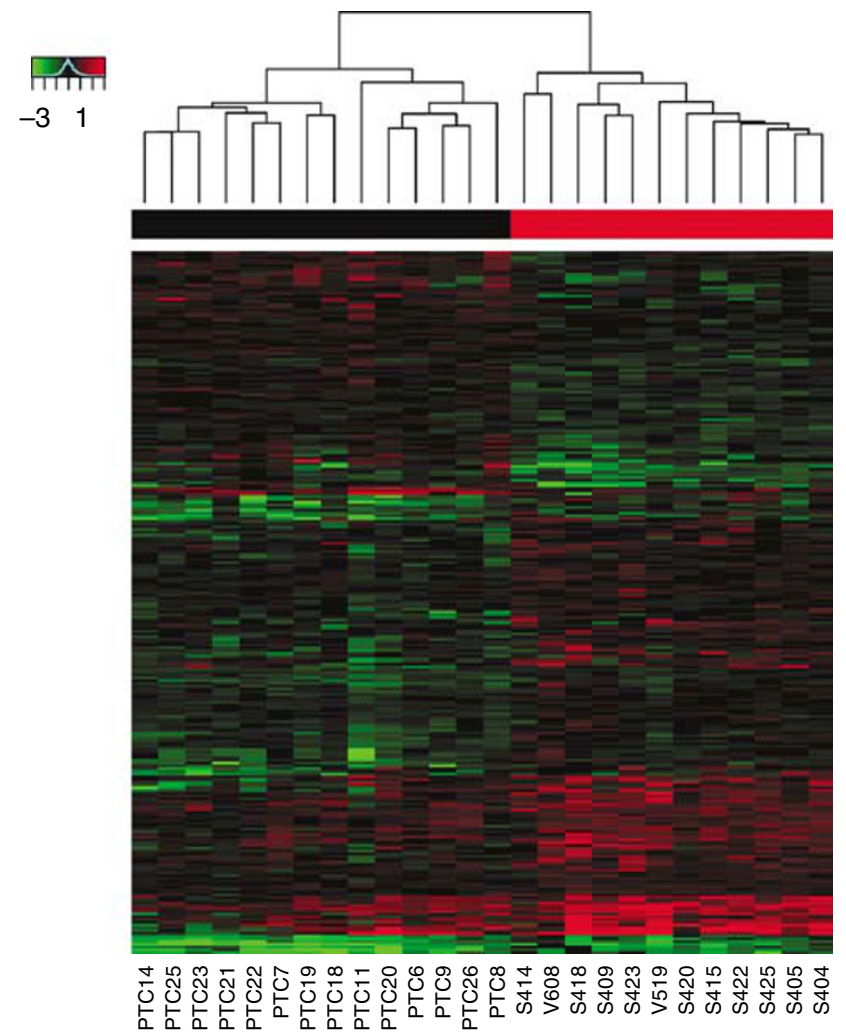

Figure 3 Top 256 most classifying genes according to GPLS/t-statistics. Chernobyl Tissue Bank samples are in red and French samples in black in the top colour bar. Data are ordered with two-way hierarchical clustering for the sake of display clarity. 


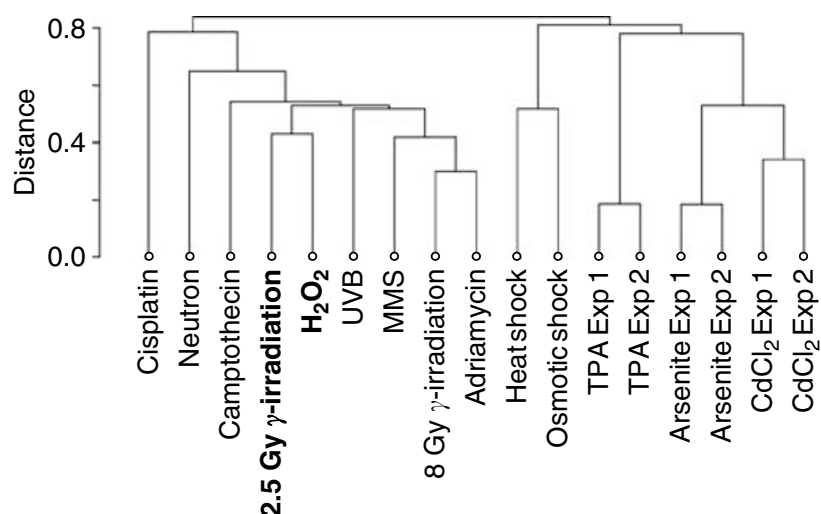

Figure 4 Hierarchical clustering of transcriptional responses of the Blymphocyte TK6 cell line to various stress agents. Expression data are from Amundson et al (2005). The responses to $200 \mu \mathrm{M}$ of $\mathrm{H}_{2} \mathrm{O}_{2}$ and $2.5 \mathrm{~Gy}$ $\gamma$-radiation cluster together. Abbreviations: MMS, methyl methanesulphonate; TPA, 12-O-tetradecanoylphorbol 13-acetate; UVB, ultraviolet $(280-320 \mathrm{~nm})$. The suffixes 'Expl' and 'Exp2' stand for replicated experiments.

Chernobyl Tissue Bank and French tumours are accurately classified on the basis of genes regulated differently in $\gamma$-radiation and $\mathrm{H}_{2} \mathrm{O}_{2}$ responses

The transcriptional responses to $\gamma$-radiation and $\mathrm{H}_{2} \mathrm{O}_{2}$ are broadly similar; however, some genes are expressed differently between the two in vitro assays. We reasoned that these expression differences may mirror subtle underlying $\gamma$-radiation and $\mathrm{H}_{2} \mathrm{O}_{2}$ susceptibility differences between CTB and French tumours that could be used for classification.

We found 293 genes in the 1451 published by Amundson et al (2005) with a fold change greater than 1.5 between the $\gamma$-radiation (2.5 Gy) and the $\mathrm{H}_{2} \mathrm{O}_{2}$ responses $(200 \mu \mathrm{M})$. These responses were measured in B lymphocytes, whereas our goal was to classify thyroid tumours. Thus, we removed immune system-specific genes from the set of 293 genes (see online Materials and Methods). This filtering left 162 genes. Among them, 118 were spotted on our microarrays. They are listed in Supplementary Table S2 and will be referred to thereafter as the $\gamma$-radiation $v s \mathrm{H}_{2} \mathrm{O}_{2}$ signature. Note that it was derived independently of our PTC data.

Next, we applied the same four classification algorithms as above except that only the independently selected 118 genes were used. Error rates (Table 2B) were comparable to those obtained in Table $2 \mathrm{~A}$, where the classifying genes were selected from a list of 8000. Again, all four algorithms classified the tumours with an error rate $\leqslant 27 \%$, GPLS/ $t$-test and LKSVM/RFE being the most accurate with an error rate of $15 \%$. This result shows a relation between the $\gamma$-radiation vs $\mathrm{H}_{2} \mathrm{O}_{2}$ signature and CTB and sporadic carcinomas distinction, which could reflect the underlying aetiology of CTB and French tumours.

\section{Chernobyl Tissue Bank and French tumours are accurately classified on the basis of $\mathbf{1 3}$ genes involved in homologous recombination}

To focus better on which elements of the DNA-damage response may differ between CTB and French tumours, we investigated if genes involved in the different DNA repair mechanisms led to accurate classification. We collected from the Human DNA Repair Genes database (Wood et al, 2001, 2005), all the genes known to be involved in base-excision repair, mismatch-excision repair, nucleotide-excision repair, homologous recombination and nonhomologous end joining. The signature from each one of these five repair mechanisms was then used to classify the CTB and French
Table 3 Homologous recombination gene signature

\begin{tabular}{ll}
\hline Symbol & Name \\
\hline XRCC2 & $\begin{array}{l}\text { X-ray repair complementing defective repair in Chinese } \\
\text { hamster cells 2 }\end{array}$ \\
SHFMI & Split hand/foot malformation (ectrodactyly) type I \\
RAD5IC & RAD5I homologue C (Saccharomyces cerevisiae) \\
MUS8I & MUS8 I endonuclease \\
RAD5ILI & RAD5I -like I (S. cerevisiae) \\
RAD5 I & RAD5 I homologue (RecA homologue, Escherichia coli) \\
& (S. cerevisiae) \\
RAD50 & RAD50 homologue (S. cerevisiae) \\
RAD54B & RAD54B homologue \\
RAD54L & RAD54-like (S. cerevisiae) \\
NBSI & Nijmegen breakage syndrome I (nibrin) \\
RAD52 & RAD52 homologue (S. cerevisiae) \\
XRCC3 & X-ray repair complementing defective repair in Chinese \\
BRCAI & hamster cells 3 \\
\hline
\end{tabular}

Only homologous recombination genes represented on our microarrays are listed (see main text).

tumours. These signatures contain few genes and were compiled from a source curated by DNA repair experts. Therefore, we skipped the gene selection step, which in turn alleviates the need for time-consuming internal cross-validation. The resulting computational gain made it tractable to run an additional statistical control: all five classification tasks were rerun 1000 times with the CTB and French labels randomly assigned to the tumours to estimate $P$-values, that is, the odds that the classification error was as low as the one observed with the actual data. Besides this, the classification proceeded exactly as above.

The classification error rates were high for base-excision repair, mismatch-excision repair and nonhomologous end joining, regardless of the algorithm (not shown). The nucleotide-excision repair signature produced an error rate of $27 \%$ with RF, but 50\% with GPLS, PAM and LKSVM. In contrast, the homologous recombination signature (Table 3) led to a classification below $31 \%$ for all four procedures, below $20 \%$ for two and equal to $15 \%$ for LKSVM (Table 2C).

The $P$-value for RF, 0.064 , was slightly above the 0.05 significance standard. All the other $P$-values were highly significant and remained below 0.02 after adjusting for the fact that five classification tasks were being examined (using Bonferonni correction, i.e., multiplying the $P$-values by 5 ). This suggests that homologous recombination, which repairs double-strand breaks, operates differently in CTB and French tumours or in the associated normal tissues. None of the homologous recombination signature genes are part of the 118 genes of the $\gamma$-radiation $v s \mathrm{H}_{2} \mathrm{O}_{2}$ signature. Thus, the homologous recombination and $\gamma$-radiation $v$ s $\mathrm{H}_{2} \mathrm{O}_{2}$ signatures are nonoverlapping. They are thus two different signatures supporting a link between radiation and the CTB/ French PTC expression differences.

\section{DISCUSSION}

We compared French and СTB tumours at the level of their global expression profiles, that is, of their overall phenotype. Hierarchical clustering and multidimensional scaling failed to uncover a largescale difference between them. Note that, would such difference exist, our preliminary study (Detours et al, 2005) would have revealed it. Thus, the conclusion of pathologists that sporadic and radiation-induced PTCs are the same type of lesions is supported by expression data.

The similarity of expression profiles on a global scale, as observed with hierarchical clustering performed on all genes, does 
not preclude that small groups of genes differ between these profiles. Supervised classification is the tool of choice to evaluate whether a group of genes can be exploited to discriminate different classes of tumours (Allison et al, 2006). Four linear classification algorithms assigned the tumours to the French or CTB groups with an error ranging from 12 to $27 \%$, and $\leqslant 15 \%$ for two algorithms. These figures are typical of properly designed microarray studies (Ntzani and Ioannidis, 2003), and compare very favourably with histopathological diagnosis accuracy in the field of thyroid tumours (Baloch et al, 2001; Hegedus, 2004; Clary et al, 2005). The stability of the gene lists uncovered through supervised classification is problematic, even in studies using hundreds of samples (Ein-Dor et al, 2005; Michiels et al, 2005). Clearly, much larger studies will be needed to list exactly and exhaustively the discriminating genes, and validate them over a larger group. Nevertheless, our results strongly suggest that such genes exist: accurate classification of CTB and French tumours is possible on the basis of their expression profiles.

Initial reports of a low BRAF mutation frequencies in postChernobyl tumours (Nikiforova et al, 2004) and of a large impact of BRAF on gene expression (Giordano et al, 2005) raised the possibility of a radiation damage signature based on the mutational status of the tumours. The frequency of BRAF V600E mutation was similar, 38\%, in our French and CTB tumours. Our analysis does not exclude the possibility of other damage signatures yet to be identified.

Radiation is a proven causing factor for PTC and a number of arguments support the view that $\mathrm{H}_{2} \mathrm{O}_{2}$-induced damage also contributes to initiate these tumours (see Introduction). Taking advantage of published data on the transcriptional responses of human lymphocytes to 13 stress agents (Amundson et al, 2005), we investigated how similar the responses to $\mathrm{H}_{2} \mathrm{O}_{2}$ and $\gamma$-radiation are. We found that among 10 genotoxic agents, $\mathrm{H}_{2} \mathrm{O}_{2}$ at $200 \mu \mathrm{M}$ elicits the response most similar to that of radiation at $2.5 \mathrm{~Gy}$. This strengthens the argument for $\mathrm{H}_{2} \mathrm{O}_{2}$ as a PTC-causing agent, as this similarity most probably mirrors a similarity of the damage inflicted by $\mathrm{H}_{2} \mathrm{O}_{2}$ and radiation. This similarity is in line with the finding that French and CTB tumours have similar global profiles. Interestingly, Xiong et al (2005) demonstrated that the number of chromatid breaks per cell following $\gamma$-irradiation was significantly higher in the lymphocytes of 57 PTC patients with no documented exposure to radiation than in the lymphocytes of healthy controls. This difference could be related to impaired homologous recombination as the $18067 \mathrm{~T}$ allele variant of XRCC3 was more frequent in 134 thyroid cancer patients than in 166 healthy patients in another study (Sturgis et al, 2005).

Transcriptional responses to $\mathrm{H}_{2} \mathrm{O}_{2}$ and $\gamma$-radiation are similar relatively to other responses to genotoxic agents. However, 118 genes regulated differently in response to $\mathrm{H}_{2} \mathrm{O}_{2}$ and radiation were uncovered and could be used to classify CTB and French tumours with an error as low as $15 \%$. This is straightforward evidence that at least some of the genes associated with these tumours are also associated with the response to their presumed respective aetiological agent.

Next, we investigated whether French and CTB tumours could be classified on the basis of five signatures covering the genes involved in the five major DNA repair mechanisms: base-excision repair, mismatch-excision repair, nucleotide-excision repair, homologous recombination and nonhomologous end joining (Wood et al, 2001, 2005). The homologous recombination signature, which shares no genes with the $\mathrm{H}_{2} \mathrm{O}_{2}$ vs $\gamma$-radiation signature, led to classification errors ranging from 15 to $31 \%$. None of the other four signatures led to accurate classification. The specificity for the homologous recombination effect, and the good classification of CTB and French tumours using the 118 genes regulated differently in response to $\mathrm{H}_{2} \mathrm{O}_{2}$ and radiation, make unlikely the confounding effect of age- or ethnicity-related factors. The fact that homologous recombination is involved in double- strand break repair fits the notion that radiation causes more double-strand breaks than $\mathrm{H}_{2} \mathrm{O}_{2}$. Nevertheless, although potential confounders are controlled for by the use of patient-matched adjacent tissues, they are not formally ruled out in our study. This will become possible in the future as tumours from younger Ukrainian patients born after 1987 become available.

Thus, several independent gene-expression signatures separate our CTB and sporadic PTCs. These subtle expression differences between CTB and French tumours must be interpreted in light of the fact that the tumours investigated were removed $>15$ years after the Chernobyl accident. Thus, any discriminating gene-expression signature had to be sustained over this time interval. DNA damage resulting from radiation, however, is typically mostly repaired within a time scale of hours. Consequently, either the reported signatures are 'damage signatures', that is, they are late results, from radiation-induced DNA damage (e.g. non- or incorrectly repaired damage), and/or they are 'susceptibility signatures', that is, they mirror radiation susceptibility factors pre-existing to the accident. The fact that one of the signature relies on the relative response to the two postulated causing agents $\left(\gamma\right.$-rays and $\left.\mathrm{H}_{2} \mathrm{O}_{2}\right)$, and that the other relies on double-strand break repair genes, suggests that these signatures are related to the tumour-initiating mechanisms. This and the longlasting presence of these signatures support the susceptibility signature model. The recent finding that different TP53 alleles are associated with radiation exposure in adult PTC from Russian-Ukrainian patients (Rogounovitch et al, 2006) also supports this view. The susceptibility model, and the corollary that radiation susceptibility varies among individuals, may partly explain why only a minority of the population most exposed to radiation in Ukraine and Belarus developed PTC.

Thus, we interpret our findings as evidence for different and detectable cancer susceptibility factors underlying CTB and French tumours, which leads to several testable predictions. Expression ratios of tumours with respect to patient-matched adjacent tissues were measured. Hence, we could uncover susceptibility signatures only to the extent that they manifest themselves differently in the cancers and their adjacent tissues. We anticipate that the direct comparison of expression levels instead of expression ratios could lead to a stronger signature, possibly involving more genes. In addition, a radiation susceptibility signature could be present in healthy cells of any type in post-Chernobyl cancer patients. This, then, suggests the possibility of developing an expression-based in vitro test for radiation susceptibility. Finally, large-scale studies could uncover the genetic or epigenetic variations underlying the phenotypic differences reported in this paper. These concepts and approaches may apply to other types of cancers.

\section{ACKNOWLEDGEMENTS}

We thank Chantal Degraef for excellent technical work. This work was supported by the Ministère de la Politique Scientifique (PAI), Action Concertée de la Communauté Française, Fond National de la Recherche Scientifique Médicale; Télévie, Fédération Belge Contre le Cancer, Fortis, and UCB-Région Wallone. VD was supported by European Union's Marie Curie Grant MEIF-CT-2003-501459.

Supplementary Information accompanies the paper on British Journal of Cancer website (http://www.nature.com/bjc).

\section{REFERENCES}

Allison DB, Cui X, Page GP, Sabripour M (2006) Microarray data analysis: from disarray to consolidation and consensus. Nat Rev Genet 7: 55-65 Ambroise C, McLachlan GJ (2002) Selection bias in gene extraction on the basis of microarray gene-expression data. Proc Natl Acad Sci USA 99: $6562-6566$ 
Amundson SA, Do KT, Vinikoor L, Koch-Paiz CA, Bittner ML, Trent JM, Meltzer P, Fornace Jr AJ (2005) Stress-specific signatures: expression profiling of p53 wild-type and -null human cells. Oncogene 24: $4572-4579$

Baloch ZW, Hendreen S, Gupta PK, LiVolsi VA, Mandel SJ, Weber R, Fraker D (2001) Interinstitutional review of thyroid fine-needle aspirations: impact on clinical management of thyroid nodules. Diagn Cytopathol 25: 231-234

Baverstock K, Egloff B, Pinchera A, Ruchti C, Williams D (1992) Thyroid cancer after Chernobyl. Nature 359: 21 -22

Caudill CM, Zhu Z, Ciampi R, Stringer JR, Nikiforov YE (2005) Dosedependent generation of RET/PTC in human thyroid cells after in vitro exposure to gamma-radiation: a model of carcinogenic chromosomal rearrangement induced by ionizing radiation. J Clin Endocrinol Metab 90: $2364-2369$

Chico Galdo V, Massart C, Jin L, Vanvooren V, Caillet-Fauquet P, Andry G, Lothaire P, Dequanter D, Friedman M, Van Sande J (2006) Acrylamide, an in vivo thyroid carcinogenic agent, induces DNA damage in rat thyroid cell lines and primary cultures. Mol Cell Endocrinol 257-258: 6-14

Chu R, Lin Y, Reddy KC, Pan J, Rao MS, Reddy JK, Yeldandi AV (1996) Transformation of epithelial cells stably transfected with $\mathrm{H}_{2} \mathrm{O}_{2}$-generating peroxisomal urate oxidase. Cancer Res 56: 4846-4852

Clary KM, Condel JL, Liu Y, Johnson DR, Grzybicki DM, Raab SS (2005) Interobserver variability in the fine needle aspiration biopsy diagnosis of follicular lesions of the thyroid gland. Acta Cytol 49: 378-382

Coclet J, Foureau F, Ketelbant P, Galand P, Dumont JE (1989) Cell population kinetics in dog and human adult thyroid. Clin Endocrinol (Oxf) 31: 655-665

Corvilain B, Collyn L, Van Sande J, Dumont JE (2000) Stimulation by iodide of $\mathrm{H}(2) \mathrm{O}(2)$ generation in thyroid slices from several species. Am J Physiol Endocrinol Metab 278: E692-E699

Corvilain B, Laurent E, Lecomte M, Van Sande J, Dumont JE (1994) Role of the cyclic adenosine $3^{\prime}, 5^{\prime}$-monophosphate and the phosphatidylinositol$\mathrm{Ca}^{2+}$ cascades in mediating the effects of thyrotropin and iodide on hormone synthesis and secretion in human thyroid slices. J Clin Endocrinol Metab 79: 152 - 159

Dahm-Daphi J, Sass C, Alberti W (2000) Comparison of biological effects of DNA damage induced by ionizing radiation and hydrogen peroxide in CHO cells. Int J Radiat Biol 76: 67-75

Detours V, Wattel S, Venet D, Hutsebaut N, Bogdanova T, Tronko MD, Dumont JE, Franc B, Thomas G, Maenhaut C (2005) Absence of a specific radiation signature in post-Chernobyl thyroid cancers. $\mathrm{Br} J$ Cancer 92: $1545-1552$

Ding B, Gentleman RC (2004) Classification using generalized partial least squares. J comput Graphical Stat 14: 280-298

Ein-Dor L, Kela I, Getz G, Givol D, Domany E (2005) Outcome signature genes in breast cancer: is there a unique set? Bioinformatics 21: 171-178

Frattini M, Ferrario C, Bressan P, Balestra D, De Cecco L, Mondellini P, Bongarzone I, Collini P, Gariboldi M, Pilotti S, Pierotti MA, Greco A (2004) Alternative mutations of BRAF, RET and NTRK1 are associated with similar but distinct gene expression patterns in papillary thyroid cancer. Oncogene 23: 7436-7440

Giordano TJ, Kuick R, Thomas DG, Misek DE, Vinco M, Sanders D, Zhu Z, Ciampi R, Roh M, Shedden K, Gauger P, Doherty G, Thompson NW, Hanash S, Koenig RJ, Nikiforov YE (2005) Molecular classification of papillary thyroid carcinoma: distinct BRAF, RAS, and RET/PTC mutation-specific gene expression profiles discovered by DNA microarray analysis. Oncogene 24: 6646 -6656

Hegedus L (2004) Clinical practice. The thyroid nodule. N Engl J Med 351: $1764-1771$

Jarzab B, Wiench M, Fujarewicz K, Simek K, Jarzab M, OczkoWojciechowska M, Wloch J, Czarniecka A, Chmielik E, Lange D, Pawlaczek A, Szpak S, Gubala E, Swierniak A (2005) Gene expression profile of papillary thyroid cancer: sources of variability and diagnostic implications. Cancer Res 65: 1587-1597

Kazakov VS, Demidchik EP, Astakhova LN (1992) Thyroid cancer after Chernobyl. Nature 359: 21

Kimura ET, Nikiforova MN, Zhu Z, Knauf JA, Nikiforov YE, Fagin JA (2003) High prevalence of BRAF mutations in thyroid cancer: genetic evidence for constitutive activation of the RET/PTC-RAS-BRAF signaling pathway in papillary thyroid carcinoma. Cancer Res 63: $1454-1457$

Kohrle J, Jakob F, Contempre B, Dumont JE (2005) Selenium, the thyroid, and the endocrine system. Endocr Rev 26: 944-984
Kumagai A, Namba H, Saenko VA, Ashizawa K, Ohtsuru A, Ito M, Ishikawa N, Sugino K, Ito K, Jeremiah S, Thomas GA, Bogdanova TI, Tronko MD, Nagayasu T, Shibata Y, Yamashita S (2004) Low frequency of BRAFT1796A mutations in childhood thyroid carcinomas. J Clin Endocrinol Metab 89: 4280-4284

Ledent C, Denef JF, Cottecchia S, Lefkowitz R, Dumont J, Vassart G, Parmentier M (1997) Costimulation of adenylyl cyclase and phospholipase $\mathrm{C}$ by a mutant alpha $1 \mathrm{~B}$-adrenergic receptor transgene promotes malignant transformation of thyroid follicular cells. Endocrinology 138: $369-378$

Lee DH, Esworthy RS, Chu C, Pfeifer GP, Chu FF (2006) Mutation accumulation in the intestine and colon of mice deficient in two intracellular glutathione peroxidases. Cancer Res 66: 9845-9851

Lima J, Trovisco V, Soares P, Maximo V, Magalhaes J, Salvatore G, Santoro M, Bogdanova T, Tronko M, Abrosimov A, Jeremiah S, Thomas G, Williams D, Sobrinho-Simoes M (2004) BRAF mutations are not a major event in post-Chernobyl childhood thyroid carcinomas. J Clin Endocrinol Metab 89: 4267 - 4271

Mahoney MC, Lawvere S, Falkner KL, Averkin YI, Ostapenko VA, Michalek AM, Moysich KB, McCarthy PL (2004) Thyroid cancer incidence trends in Belarus: examining the impact of Chernobyl. Int J Epidemiol 33: $1025-1033$

Michiels S, Koscielny S, Hill C (2005) Prediction of cancer outcome with microarrays: a multiple random validation strategy. Lancet 365 $488-492$

Mondello C, Guasconi V, Giulotto E, Nuzzo F (2002) Gamma-ray and hydrogen peroxide induction of gene amplification in hamster cells deficient in DNA double strand break repair. DNA Repair (Amst) 1: $483-493$

Neumann CA, Krause DS, Carman CV, Das S, Dubey DP, Abraham JL, Bronson RT, Fujiwara Y, Orkin SH, Van Etten RA (2003) Essential role for the peroxiredoxin Prdx1 in erythrocyte antioxidant defence and tumour suppression. Nature 424: 561-565

Nikiforov YE (2002) RET/PTC rearrangement in thyroid tumors. Endocr Pathol 13: 3-16

Nikiforov YE, Rowland JM, Bove KE, Monforte-Munoz H, Fagin JA (1997) Distinct pattern of ret oncogene rearrangements in morphological variants of radiation-induced and sporadic thyroid papillary carcinomas in children. Cancer Res 57: 1690-1694

Nikiforova MN, Ciampi R, Salvatore G, Santoro M, Gandhi M, Knauf JA, Thomas GA, Jeremiah S, Bogdanova TI, Tronko MD, Fagin JA, Nikiforov YE (2004) Low prevalence of BRAF mutations in radiation-induced thyroid tumors in contrast to sporadic papillary carcinomas. Cancer Lett 209: $1-6$

Ntzani EE, Ioannidis JP (2003) Predictive ability of DNA microarrays for cancer outcomes and correlates: an empirical assessment. Lancet 362: $1439-1444$

Powell N, Jeremiah S, Morishita M, Dudley E, Bethel J, Bogdanova T, Tronko M, Thomas G (2005) Frequency of BRAF T1796A mutation in papillary thyroid carcinoma relates to age of patient at diagnosis and not to radiation exposure. J Pathol 205: 558-564

Quinn MT, Ammons MC, Deleo FR (2006) The expanding role of NADPH oxidases in health and disease: no longer just agents of death and destruction. Clin Sci (Lond) 111: 1-20

Rogounovitch TI, Saenko VA, Ashizawa K, Sedliarou IA, Namba $\mathrm{H}$, Abrosimov AY, Lushnikov EF, Roumiantsev PO, Konova MV, Petoukhova NS, Tchebotareva IV, Ivanov VK, Chekin SY, Bogdanova TI, Tronko MD, Tsyb AF, Thomas GA, Yamashita S (2006) TP53 codon 72 polymorphism in radiation-associated human papillary thyroid cancer. Oncol Rep 15: $949-956$

Rosenbaum E, Hosler G, Zahurak M, Cohen Y, Sidransky D, Westra WH (2005) Mutational activation of BRAF is not a major event in sporadic childhood papillary thyroid carcinoma. Mod Pathol 18: $898-902$

Ruschhaupt M, Huber W, Poustka A, Mansmann U (2004) A compendium to ensure computational reproducibility in high-dimensional classification tasks. Stat Appl Genet Mol Biol 3, article 37 www.bepress.com/ sagmb/vol3/iss1/art37/

Simon R, Radmacher MD, Dobbin K, McShane LM (2003) Pitfalls in the use of DNA microarray data for diagnostic and prognostic classification. J Natl Cancer Inst 95: 14- 18

Soares P, Trovisco V, Rocha AS, Lima J, Castro P, Preto A, Maximo V, Botelho T, Seruca R, Sobrinho-Simoes M (2003) BRAF mutations and RET/PTC rearrangements are alternative events in the etiopathogenesis of PTC. Oncogene 22: 4578-4580 
Sturgis EM, Zhao C, Zheng R, Wei Q (2005) Radiation response genotype and risk of differentiated thyroid cancer: a case-control analysis. Laryngoscope 115: 938 - 945

Su AI, Wiltshire T, Batalov S, Lapp H, Ching KA, Block D, Zhang J, Soden R, Hayakawa M, Kreiman G, Cooke MP, Walker JR, Hogenesch JB (2004) A gene atlas of the mouse and human protein-encoding transcriptomes. Proc Natl Acad Sci USA 101: $6062-6067$

Thomas GA, Williams ED, Becker DV, Bogdanova TI, Demidchik EP, Lushnikov E, Nagataki S, Ostapenko V, Pinchera A, Souchkevitch G, Tronko MD, Tsyb AF, Tuttle M, Yamashita S (2000) Chernobyl tumor bank. Thyroid 10: 1126-1127

Tibshirani R, Hastie T, Narasimhan B, Chu G (2002) Diagnosis of multiple cancer types by shrunken centroids of gene expression. Proc Natl Acad Sci USA 99: 6567-6572

Turner DR, Dreimanis M, Holt D, Firgaira FA, Morley AA (2003) Mitotic recombination is an important mutational event following oxidative damage. Mutat Res 522: $21-26$

Tusher VG, Tibshirani R, Chu G (2001) Significance analysis of microarrays applied to the ionizing radiation response. Proc Natl Acad Sci USA 98: $5116-5121$
United Nations Scientific Committee of the Effect Of Atomic Radiation (2000) Sources, Effect and Risk of Ionizing Radiations. New York: United Nations

Williams ED, Abrosimov A, Bogdanova T, Demidchik EP, Ito $M$, LiVolsi V, Lushnikov E, Rosai J, Sidorov Y, Tronko MD, Tsyb AF, Vowler SL, Thomas GA (2004) Thyroid carcinoma after Chernobyl latent period, morphology and aggressiveness. $\mathrm{Br} J$ Cancer 90: $2219-2224$

Wood RD, Mitchell M, Lindahl T (2005) Human DNA repair genes. Mutat Res 577: 275-283

Wood RD, Mitchell M, Sgouros J, Lindahl T (2001) Human DNA repair genes. Science 291: $1284-1289$

Xing M (2005) BRAF mutation in thyroid cancer. Endocr Relat Cancer 12: $245-262$

Xiong P, Zheng R, Wang LE, Bondy ML, Shen H, Borer MM, Wei Q, Sturgis EM (2005) A pilot case-control study of gamma-radiation sensitivity and risk of papillary thyroid cancer. Thyroid 15: $94-99$

Zhang H, Yu CY, Singer B (2003) Cell and tumor classification using gene expression data: construction of forests. Proc Natl Acad Sci USA 100: $4168-4172$ 